\title{
The effects of personalized sprint interval training and combined aerobic endurance and resistance training on insulin resistance and glycated hemoglobin in women with type 2 diabetes
}

\author{
Hadi Ghaedi $^{*}{ }^{\circledR}$, Siamak Takesh $^{2}{ }^{\mathbb{D}}$, Ebrahim Banitalebi $^{3}{ }^{\circledR}$ \\ ${ }^{1}$ Assistant Professor of Exercise Physiology, Lamerd Branch, Islamic Azad University, Lamerd, Iran. \\ ${ }^{2}$ Department of Physical Education, Mahshahr Branch, Islamic Azad University, Mahshahr, Iran. \\ ${ }^{3}$ Associate Professor in Exercise Physiology, Shahrekord University, Iran.
}

*Corresponding Author: Hadi Ghaedi, Department of Physical Education, Lamerd Branch, Islamic Azad University. Tel: 09177828667, Email: ghaedi.hadi@gmail.com

\begin{abstract}
Background and aims: Exercise training is a well-established therapeutic tool for treating type 2 diabetes. The purpose of this study is to examine the beneficial effects of personalized sprint interval training (SIT) and combined aerobic endurance and resistance training (Com) on insulin resistance and glycated hemoglobin $\mathrm{A} 1 \mathrm{c}(\mathrm{HbA} 1 \mathrm{c})$ concentration in women with type 2 diabetes.

Methods: Fifty-two overweight female type 2 diabetic patients (age 45-60 years and body mass index [BMI] $>30$ ) with $\mathrm{HbA} 1 \mathrm{c}$ value of $6.5 \%$ or higher and fasting blood glucose $(\mathrm{FBG}) \geq 126 \mathrm{mg} / \mathrm{dL}(7.0 \mathrm{mmol} / \mathrm{L})$ were selected. Participants were recruited from patients filed in the outpatient department of Shahrekord Hospital (Shahrekord, Iran) in 2016. The participants were assigned to SIT ( $n=17)$, Com $(n=17)$, and control groups $(n=18)$ according to HbA1c levels. The exercises included 10 weeks of Com and SIT.

Results: HbA1c concentrations decreased significantly in SIT $(P=0.002)$ and Com $(P=0.006)$ groups. The dependent $t$-test revealed that differences were significant for the FBG in the SIT groups $(P<0.001)$. Serum insulin levels showed significant increases in the SIT $(P<0.001)$ and Com $(P<0.001)$ groups. Data showed significant differences in homeostasis model assessment-estimated insulin resistance (HOMA-IR) in SIT $(P<0.001)$ and Com $(P<0.001)$ groups. The analysis of covariance (ANCOVA) test showed significant differences in serum insulin $(\mathrm{F}=3.622, P=0.02)$ and HOMA-IR $(\mathrm{F}=5.511, P=0.0001)$ levels and no significant difference in HbA1c $(\mathrm{F}=0.597, P=0.556)$ and $\mathrm{FBG}$ concentrations $(\mathrm{F}=1.853, P=0.171)$.

Conclusion: Results highlight that individualized exercise training, independent of the mode of training, is effective in improving glycemic control in overweight patients with type 2 diabetes.

Keywords: Personalized SIT, Combined training, Resistance training, HbA1c, Diabetes
\end{abstract}

Received: 27 October 2019, Accepted: 18 December 2019, ePublished: 29 June 2020

\section{Introduction}

Type 2 diabetes (T2D) as a global health issue is related to various severe medical problems such as cardiovascular disease (CVD), neuropathy, retinopathy, and kidney disease (1). While there is a lot of scientific evidence to support that exercise training interventions such as resistance and aerobic training or combined aerobic and resistance exercises within the same exercise session could improve glycemic index compared to sedentary individuals, comparatively little information is available to determine the optimum frequency, intensity, time, or type of exercise (2-5). Traditional exercise training is difficult to sustain due to lack of time (6). The manipulation of variables following exercise training has created different types of training. High-intensity interval training (HIIT) which is typically defined as exercise at $85 \%-100 \%$ maximum heart rate (MHR) (7) has potential to improve glycemic control. There seems to be accumulating evidence that glycemic control is improved by HIIT in type 2 diabetic individuals $(8,9)$.

It has been shown that $15 \%-20 \%$ of patients with type 2 diabetes fail to improve their glucose homeostasis following exercise training (10). Some studies demonstrated that despite using homogeneous populations, there were heterogeneous responses to exercise program (11). Recently, it has been demonstrated that $10 \%-20 \%$ of people are nonresponders to exercise programs, meaning that some exercise training protocol may not have beneficial effects on metabolic syndromes (11). The existence of nonresponders to exercise program demonstrates the need for an individualized exercise program as personalized medicine for the maintenance of

(C) 2020 The Author(s); Published by Shahrekord University of Medical Sciences. This is an open-access article distributed under the terms of the Creative Commons Attribution License (http://creativecommons.org/licenses/by/4.0), which permits unrestricted use, distribution, and reproduction in any medium, provided the original work is properly cited. 
normal glucose homeostasis. Buford et al concluded that tailored exercise strategies must be considered in exercise interventions (12). In addition, because of the prevalence of adverse responses to regular exercise training, exercise prescription should be personalized (13).

American Diabetes Association (ADA) defined partial remission as sub-diabetic hyperglycemia (fasting plasma glucose of 100-125 mg/dL and HbA1c of 6.5\%) of at least 1 year duration in the absence of active pharmacologic therapies (14). Numerous studies that focused on exercise interventions for type 2 diabetic patients utilized standardbased exercise programs and did not address the issue of remission and improvement in overall glycemic control typically observed in type 2 diabetic patients (15-17). It seems that even the exercise guidelines recommended by ADA could not improve glycemic status to prediabetic and normal levels (18). On the other hand, even HIIT which has better effects on diabetic patient fails to change glycemic control and improve it to normal levels (19). Because of complexity and variability in physiological and molecular responses to various exercise treatments, we considered evaluating sprint interval training (SIT) because it induces more robust fitness adaptations compared to moderate-intensity aerobic training (20). Secondly, we hypothesized that both SIT and combined aerobic and resistance training would be associated with metabolic/ physiological parameters, body composition, and physical fitness benefits compared to the control group.

\section{Objectives}

In the present study, the patients completed one of two different personalized training regimes: SIT or Com. We hypothesized that the two different training regimes would produce beneficial effects in diabetic patients. Therefore, the purpose of this study is to examine the effects of personalized SIT and Com on insulin resistance and $\mathrm{HbA} 1 \mathrm{c}$ concentration in diabetic female patients.

\section{Materials and Methods}

\section{Experimental Design}

The experimental design consisted of familiarization period ( 2 weeks), baseline testing, and an 8-week exercise training intervention. This program was done three times a week for 45 minutes per session. This study was a quasiexperimental research with pre-test and post-test design. Purposive sampling with random assignment was used. Participants were randomly assigned to the three groups following pre-testing.

\section{Patients and Methods}

This study was a single-blind randomized clinical trial conducted in Shahrekord University (2016), on the basis of the CONSORT Statement (Figure 1). Participants were recruited from patients filed in the outpatient department of Shahrekord Hospital (Shahrekord, Iran) in 2016. Among 150 patients screened, 52 overweight female type 2 diabetic patients (age: 45-60 years, body mass index $[\mathrm{BMI}]>25$ ) with an $\mathrm{HbA1c}$ value of $6.5 \%$ or above and fasting blood glucose $(\mathrm{FBG}) \geq 126 \mathrm{mg} / \mathrm{dL}$ $(7.0 \mathrm{mmol} / \mathrm{L})$ were selected. A total of 27 subjects were treated with oral drugs (metformin and Glibenclamide), 20 were treated with insulin injections, and 5 were treated

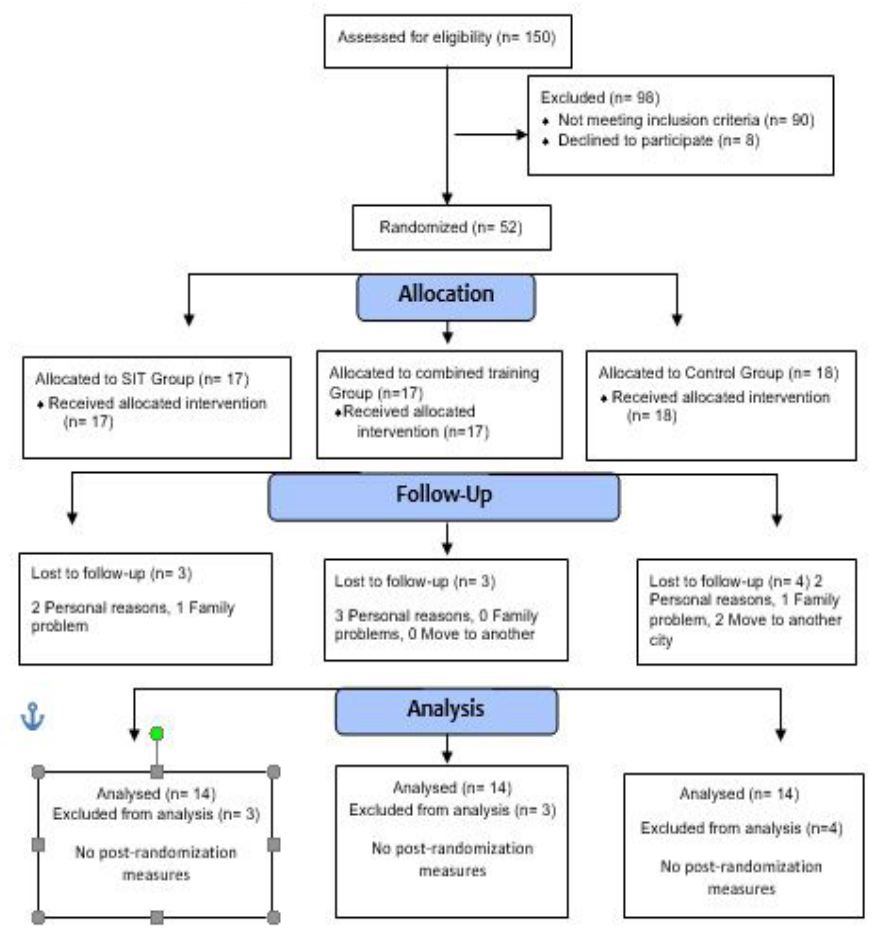

Figure 1. CONSORT 2010 Flow Diagram. 
with combination therapy of insulin injection and oral drugs. The main criteria for exclusion were $\mathrm{BMI}<25$, age $>60$ years, having uncontrolled high blood pressure, severe CVDs or cancer. In addition, in accordance with previous studies (21-23), a sample size of 10 to 20 participants could clinically provide a statistical power of $80 \%$ for finding the effect of SIT protocol versus combined training regimes and a potential difference of $2 \%$ following a $10-$ week exercise training program. Based on the power and sample size calculation, 17 subjects were determined to be included per group based on a predicted dropout rate of $20 \%$ in this study.

Of 150 recruited participants, 54 subjects met the inclusion criteria (Figure 1). Eligible participants were informed about study program, the possible risks, and benefits involved in the trial. Participants were assured that all answers would be kept strictly confidential.

The block randomization method (6 blocks) was conducted by a research assistant who was not involved in this research using a computer-generated random number sequence. The participants were assigned to three different groups (SIT group $(\mathrm{n}=17)$, the $\mathrm{A}+\mathrm{R}$ group $(\mathrm{n}=$ $17)$, or the control group $(\mathrm{n}=18)$ ) according to HbA1c level. Sequential treatment allocations were enclosed in numbered, opaque, sealed envelopes, and distributed by the research assistant to the groups after the baseline testing (Figure 1).

After baseline assessments, the participants were assigned to SIT group $(\mathrm{n}=17$, age: $55.35 \pm 5.94$ years, height: $162.93 \pm 67.97 \mathrm{~cm}$, body mass: $73.06 \pm 21.62$ kg, BMI: $29.57 \pm 2.77 \mathrm{~kg} \cdot \mathrm{m}^{-2}$, HbA1c: $9.64 \pm 1.08 \%$, FBG: $210.07 \pm 32.90 \mathrm{mg} / \mathrm{dL})$, Com group $(\mathrm{n}=17$, age: $54.14 \pm 5.43$ years, height: $160.57 \pm 4.98 \mathrm{~cm}$, body mass: $76.30 \pm 9.58 \mathrm{~kg}$, BMI: $30.57 \pm 2.97 \mathrm{~kg} . \mathrm{m}^{-}$ 2, HbAlc: $9.49 \pm 0.86 \%$, FBG: $214.64 \pm 27.67 \mathrm{mg} /$ $\mathrm{dL})$, and control group $(\mathrm{n}=18$, age: $55.71 \pm 6.40$ years, height: $156.42 \pm 12.82 \mathrm{~cm}$, body mass: $71.44 \pm 13.20 \mathrm{~kg}$, BMI: $29.70 \pm 4.17 \mathrm{~kg} . \mathrm{m}^{-2}$, HbA1c: $9.10 \pm 0.51 \%$, FBG: $200.86 \pm 46.88 \mathrm{mg} / \mathrm{dL}$ ) according to HbA1c levels. The inclusion criteria were being sedentary and not having exercised for more than 20 minutes a week over the past 6 months. The subjects were familiarized with study procedures and were informed about the possible risks and benefits involved in this study both verbally and in writing. They were assured that all answers would be kept strictly confidential. Patients were asked to sign an informed consent form.

Patients received no dietary intervention, but they were instructed not to change their dietary habits during the study. In order to minimize diet-induced variability in glycemic indexes and other tests, they were instructed to consume the same dietary intake for two days before pretest and posttest.

During the experimental period, 10 patients dropped out of the study (3 in the combined training group, 3 in the SIT training group, and 4 in the control group) due to illness and failure to follow up.

Forty-two females with stable type 2 diabetes, all free of exercise limiting or diabetes-related complications such as musculoskeletal impairment, vascular disease or orthopedic limitations that could cause interference effects on their participation in the exercise program or laboratory test results, were eligible to participate in this study and enroll in a 30-session rehabilitation program. Body mass, BMI, body fat, and waist circumference (WC) are presented in Table 1.

\section{Exercise training protocols}

The two different exercise interventions included 10 weeks of either combined (resistance plus aerobic) training or SIT.

Each combined training session consisted of 10 minutes of general warm-up (50\% HRR) and 50 minutes of exercise training, and 10 minutes of cooling down (40\% HRR). All participants attended a familiarization session for becoming familiar with training procedures, intensity, and equipment.

In weeks $1-2$, aerobic training was performed at $60 \%$ heart rate reverse (HRR) calculated by Karvonen formula (24) (exercise heart rate $=\% 60(\mathrm{MHR}-$ resting heart rate) + resting heart rate) for 20 minutes on a cycling ergometer, three times a week. During weeks 3-10, the intensity increased by $10 \%$ HRR. The aerobic training was personalized by increments, when the subjects could complete exercise while maintaining target heart rate, the time was increased by $10 \%$.

Resistance training consisted of exercising twice a week for 10 weeks. During weeks 1-2, resistance training was performed at 15-RM calculated by the Brzycki equation $[1-\mathrm{RM}=$ Weight $\div(1.0278-(0.0278 \times$ number of

Table 1. Exercise training interventions

\begin{tabular}{|c|c|c|c|c|c|c|c|c|c|c|c|}
\hline \multirow{2}{*}{$\begin{array}{l}\text { Week } \\
\text { (No) }\end{array}$} & \multicolumn{5}{|c|}{ Resistance training program } & \multicolumn{3}{|c|}{ Aerobic endurance training } & \multicolumn{3}{|c|}{ SIT } \\
\hline & Set & $\begin{array}{c}\text { Repetition } \\
\text { (Number) }\end{array}$ & Rest between (min) & weight & $\begin{array}{c}\text { Frequency } \\
\text { (days/week) }\end{array}$ & $\begin{array}{l}\text { Duration } \\
\text { (min) }\end{array}$ & $\begin{array}{l}\text { Intensity } \\
\text { (MHR \%) }\end{array}$ & $\begin{array}{l}\text { Frequency } \\
\text { (day/week) }\end{array}$ & $\begin{array}{l}\text { Duration } \\
\text { (second) }\end{array}$ & $\begin{array}{l}\text { Intensity } \\
(\text { MHR \%) }\end{array}$ & $\begin{array}{l}\text { Frequency } \\
\text { (day/week) }\end{array}$ \\
\hline $1-2$ & 1 & 15 & $2-3$ & 15-RM & 2 & $15-20$ & 60 & 3 & $4 \times 30 \mathrm{~s}$ & $75 \%$ & 3 \\
\hline $3-4$ & 2 & 15 & $2-3$ & $15-R M$ & 2 & 25 & 60 & 3 & $4 \times 30 \mathrm{~s}$ & $75 \%$ & 3 \\
\hline $5-6$ & 3 & 12 & $2-3$ & 12-RM & 2 & 30 & 70 & 3 & $4 \times 30 s$ & $75 \%$ & 3 \\
\hline 7-8 & 3 & 12 & $2-3$ & 12-RM & 2 & 30 & 70 & 3 & $4 \times 30 \mathrm{~s}$ & $75 \%$ & 3 \\
\hline $9-10$ & 3 & 10 & $2-3$ & 10-RM & 2 & 30 & 70 & 3 & $4 \times 30 s$ & $75 \%$ & 3 \\
\hline
\end{tabular}

RM: Repetition maximum, MHR: Maximum heart rate, SIT: Sprint interval training 
repetitions))] (25), three times a week. During weeks 3-10, the intensity increased by $70 \% 1-\mathrm{RM}$. The resistance training was performed as follows: bench press, leg press, bent over lateral pull-down, bilateral biceps curl, and bilateral triceps push down. The strength was measured by $1-\mathrm{RM}$ test. The resistance training was performed at 40 $\%$ of 1-RM for 1-2 week. Each patient received their own personalized exercise program in a training diary that had to be completed at each training session. For personalizing resistance training, when the patients could perform more than eight repetitions while maintaining proper form and full range of motions, the load was increased by $2.5-5 \mathrm{~kg}$ (26).

SIT protocol was done three times per week on cycle ergometers (Seca cardiotest 100, model 545) for 10 weeks. SIT consisted of a 5 -minute warm-up at 50 revolutions per minute $(\mathrm{rpm})$ followed by $4 \times 30$ seconds of high-intensity interval cycling sprints, interspersed with a 2-minute recovery and 4-minute cool-down $(25 \mathrm{~W})$. Patients who completed the three intervals in the first SIT session had their wattage (cycling with $7.5 \%$ of body weight) (27) adjusted upward by $10 \%$ increments based on performance and perceived effort. Furthermore, for patients who were unable to maintain the required $>120 \mathrm{rpm}$ for any interval, wattage was adjusted down by $10 \%$ increments based on the same criteria. During the 10 weeks of SIT, if a patient completed three intervals maintaining more than $120 \mathrm{rpm}$ on two consecutive sessions, the wattage was adjusted upward by $10 \%$ increments to ensure that maximum intensity exerted during each session (11).

\section{Measurements}

Body fat percentage (BF \%) was measured to the nearest $0.5 \mathrm{~mm}$ at three sites: abdominal, thigh, and suprailiac (Lafayette Skinfold Caliper II).

\section{Exercise testing protocols}

To measure aerobic capacity, a Modified Bruce protocol treadmill test was used (28). To measure the lower limb strength and upper limb strength, a 1-RM leg press test (29) and a 1-RM bench press test were used (30).

\section{Blood analysis}

In order to examine serum glucose, insulin, and HbA1c, blood samples $(10 \mathrm{~mL})$ of the subjects were collected 24 hours before exercise training and 48 hours after the last session of the training program in a 12 -hour fasting state from the antecubital vein in a sitting position. The blood samples were then centrifuged at $500 \mathrm{~g}$ for 10 minutes at $4^{\circ} \mathrm{C}$ to separate the serum.

The levels of FBG were measured using Glucose Oxidase Assay Kit (Pars Azmoon, Tehran, Iran), with an autoanalyzer device (Hitachi ${ }^{\oplus}$, model 704, 902 made in Japan). Serum insulin concentrations were determined by ELISA kit. HbA1c levels were measured using commercial
ELISA kits. Insulin resistance (HOMA-IR) was calculated along with blood fasting glucose $(\mathrm{mg} / \mathrm{dL})$ and fasting insulin $(\mathrm{mU} / \mathrm{L})$ values using the validated calculator (available at http://www.dtu.ox.ac.uk) in those participants who were not taking exogenous insulin $(n=22)$.

\section{Statistical Analyses}

All values are represented as mean \pm standard deviation (SD). The Kolmogorov-Smirnov test was used to test the normality of the data. Data were analyzed by dependent $t$ test to compare pre-test and post-test values in each group. The analysis of covariance (ANCOVA) test was used to compare the changes in experimental and control training groups after 10 weeks. When a significant $\mathrm{F}$ value was achieved, Fisher's least significant difference (LSD) test was used to find the differences between groups.

\section{Results}

The results were based on the observations of 14 participants in control, 14 participants in SIT and 14 people in combined training groups. The $P$ values for comparisons of anthropometric characteristics before and after training within and between groups are reported in Table 2.

The effects of a 10-week combined resistance/ endurance training and SIT program on glycosylated hemoglobin (HbA1c) concentration and insulin resistance in female diabetic patients are shown in Table 3. HbA1c concentrations changed significantly in SIT $(P=0.002)$ and $\operatorname{Com}(P=0.006)$ groups.

The dependent $t$ test showed that the differences in the FBG in the SIT group were significant $(P<0.001)$ following a 10 -week exercise training protocol. Paired $t$ tests showed that the serum insulin levels significantly increased in the SIT $(P<0.001)$ and Com $(P<0.001)$ groups following exercise training.

In addition, the results of a paired $t$-test showed significant differences in HOMA-IR in SIT $(P<0.001)$ and Com $(P=0.001)$. Furthermore, the results of ANCOVA test showed that there was no significant difference in HbA1c concentrations $(F=0.597, P=0.556)$ and $F B G$ concentrations $(\mathrm{F}=1.853, P=0.171)$. However, the results of ANCOVA test showed that there were significant differences between groups in insulin $(\mathrm{F}=3.622, P=$ 0.02) and HOMA-IR $(\mathrm{F}=5.511, P=0.0001)$.

\section{Discussion}

This study investigated the idea of integrating adaptability and personalization into the exercise treatments for type 2 diabetes patients and investigating to what extent the adaptive personalized training may contribute to successful metabolic improvements. However, for many patients with type 2 diabetes, the presence of non-responders to exercise showed that some people derive less metabolic benefit from exercise training. Patients who need any 
Table 2. The comparison of changes in the anthropometric variables before and after 10 weeks of exercise training

\begin{tabular}{|c|c|c|c|c|c|}
\hline \multirow{2}{*}{ Variables } & \multirow{2}{*}{ Groups } & \multicolumn{2}{|c|}{ Mean \pm SD } & \multirow{2}{*}{$\begin{array}{c}\text { Within group } \\
\text { (P value })\end{array}$} & \multirow{2}{*}{$\begin{array}{c}\text { Between groups } \\
\quad(P \text { value })\end{array}$} \\
\hline & & Pre-test & Post-test & & \\
\hline \multirow{3}{*}{$\begin{array}{l}\text { Body mass } \\
(\mathrm{kg})\end{array}$} & $\mathrm{SIT}(\mathrm{n}=14)$ & $73.06 \pm 21.62$ & $77.00 \pm 12.34$ & 0.377 & \multirow{3}{*}{0.197} \\
\hline & $\operatorname{Com}(n=14)$ & $76.30 \pm 9.58$ & $75.55 \pm 9.23$ & $0.032^{*}$ & \\
\hline & Control $(n=14)$ & $71.44 \pm 13.20$ & $71.26 \pm 13.06$ & 0.639 & \\
\hline \multirow{3}{*}{$\begin{array}{l}\text { BMI } \\
\left(\mathrm{kg} / \mathrm{m}^{2}\right)\end{array}$} & $\mathrm{SIT}(\mathrm{n}=14)$ & $29.57 \pm 2.77$ & $28.97 \pm 3.39$ & 0.248 & \multirow{3}{*}{0.603} \\
\hline & Com $(n=14)$ & $30.57 \pm 2.97$ & $31.58 \pm 8.61$ & 0.680 & \\
\hline & Control $(n=14)$ & $29.70 \pm 4.17$ & $29.13 \pm 4.41$ & 0.189 & \\
\hline \multirow{3}{*}{$\begin{array}{l}\text { Body fat } \\
(\%)\end{array}$} & $\mathrm{SIT}(\mathrm{n}=14)$ & $42.64 \pm 2.23$ & $41.14 \pm 4.34$ & 0.317 & \multirow{3}{*}{0.505} \\
\hline & Com $(n=14)$ & $31.32 \pm 4.63$ & $27.99 \pm 2.36$ & 0.347 & \\
\hline & Control $(n=14)$ & $43.92 \pm 2.49$ & $42.64 \pm 4.95$ & 0.379 & \\
\hline \multirow{3}{*}{$\begin{array}{l}\text { WC } \\
(\mathrm{cm})\end{array}$} & $\operatorname{SIT}(n=14)$ & $102.21 \pm 10.67$ & $95.14 \pm 9.48$ & $0.001^{* *}$ & \multirow{3}{*}{$0.004^{* *}$} \\
\hline & Com $(n=14)$ & $101.14 \pm 10.16$ & $96.00 \pm 6.55$ & $0.001^{* *}$ & \\
\hline & Control $(n=14)$ & $97.42 \pm 11.08$ & $97.27 \pm 9.78$ & 0.901 & \\
\hline \multirow{3}{*}{ WHR } & SIT $(n=14)$ & $1.01 \pm 0.13$ & $0.93 \pm 0.06$ & $0.001^{* *}$ & \multirow{3}{*}{$0.002^{* *}$} \\
\hline & Com $(n=14)$ & $1.01 \pm 0.25$ & $0.97 \pm 0.07$ & $0.001^{* *}$ & \\
\hline & Control $(n=14)$ & $1.01 \pm 0.018$ & $0.98 \pm 0.07$ & 0.08 & \\
\hline
\end{tabular}

SIT: sprint interval training; Com: resistance and aerobic endurance training; Control: subjects who did not participate in exercise training; BMI: body mass index;

WC: waist circumference; WHR: waist-hip ratio.

* Significant difference between two groups $(P<0.05)$. ** Significant difference between two groups $(P<0.01)$.

Table 3. The comparison of changes in the glycemic variables before and after 10 weeks of exercise training

\begin{tabular}{|c|c|c|c|c|c|c|c|c|}
\hline \multirow{2}{*}{ Variables } & \multirow{2}{*}{ Groups } & \multirow{2}{*}{$\begin{array}{c}\text { Pretest } \\
\text { Mean } \pm \text { SD }\end{array}$} & \multirow{2}{*}{$\begin{array}{c}\text { Posttest } \\
\text { Mean } \pm \text { SD }\end{array}$} & \multirow{2}{*}{$\begin{array}{l}\text { Within group } \\
(P \text {-value })\end{array}$} & \multicolumn{2}{|c|}{ Remission (\%) } & \multirow{2}{*}{$\mathbf{F}$} & \multirow{2}{*}{$\begin{array}{c}\text { Between groups } \\
\quad(P \text { value })\end{array}$} \\
\hline & & & & & prediabetes & normal & & \\
\hline \multirow{3}{*}{$\begin{array}{l}\mathrm{HbA} 1 \mathrm{c} \\
\%(\mathrm{mmol} / \mathrm{mol})\end{array}$} & $\operatorname{SIT}(n=14)$ & $\begin{array}{c}9.64 \pm 1.08 \\
(82)\end{array}$ & $\begin{array}{c}7.82 \pm 0.93 \\
(63)\end{array}$ & $0.002^{* *}$ & 14.25 & 7.14 & \multirow{3}{*}{0.597} & \multirow{3}{*}{0.556} \\
\hline & Com $(n=14)$ & $\begin{array}{c}9.49 \pm 0.86 \\
(83)\end{array}$ & $\begin{array}{c}8.25 \pm 1.22 \\
(67)\end{array}$ & $0.006^{* *}$ & 7.14 & 0 & & \\
\hline & Control $(n=14)$ & $\begin{array}{c}9.10 \pm 0.51 \\
(76)\end{array}$ & $\begin{array}{c}9.12 \pm 1.41 \\
(80)\end{array}$ & 0.231 & 7.14 & 0 & & \\
\hline \multirow{3}{*}{$\begin{array}{l}\text { FBG } \\
(\mathrm{mg} / \mathrm{dL})\end{array}$} & $\operatorname{SIT}(n=14)$ & $210.07 \pm 32.90$ & $137.36 \pm 32.95$ & $0.001^{* *}$ & 42.85 & 7.14 & \multirow{3}{*}{1.853} & \multirow{3}{*}{0.171} \\
\hline & $\operatorname{Com}(n=14)$ & $214.64 \pm 27.67$ & $163.86 \pm 71.47$ & 0.062 & 35.71 & 7.14 & & \\
\hline & Control $(\mathrm{N}=14)$ & $200.86 \pm 46.88$ & $190.50 \pm 59.71$ & 0.690 & 0 & 0 & & \\
\hline \multirow{3}{*}{$\begin{array}{l}\text { Serum insulin } \\
(\mu \bigcup / m L)\end{array}$} & SIT $(n=14)$ & $10.08 \pm 5.43$ & $8.18 \pm 5.75$ & $0.001^{* *}$ & 35.71 & 64.28 & \multirow{3}{*}{3.622} & \multirow{3}{*}{$0.02 *$} \\
\hline & Com $(n=14)$ & $10.37 \pm 5.35$ & $8.83 \pm 7.60$ & $0.001^{* *}$ & 21.42 & 78.57 & & \\
\hline & Control $(n=14)$ & $9.55 \pm 4.05$ & $9.16 \pm 3.75$ & 0.378 & 8.1 & 0 & & \\
\hline \multirow{3}{*}{ HOMA-IR } & $\mathrm{SIT}(\mathrm{n}=14)$ & $01.63 \pm 0.83$ & $1.15 \pm 0.74$ & $0.001^{* *}$ & 10.02 & 6.76 & \multirow{3}{*}{5.511} & \multirow{3}{*}{$0.0001^{* *}$} \\
\hline & Com $(n=14)$ & $01.13 \pm 0.28$ & $0.95 \pm 0.24$ & $0.001^{* *}$ & 8.23 & 0 & & \\
\hline & Control $(n=14)$ & $1.39 \pm 0.63$ & $1.42 \pm 0.71$ & 0.732 & 4.65 & 0 & & \\
\hline
\end{tabular}

SIT: sprint interval training; Com: resistance and aerobic endurance training; Control: subjects who did not participate in exercise training; HbA1c: glycated hemoglobin A1c; FBG: fasting blood glucose; HOMA-IR: homeostasis model assessment for insulin resistance.

* Significant difference between two groups $(P<0.05)$. ** Significant difference between two groups $(P<0.01)$.

kind of exercise therapy are individuals with their own characteristics and needs.

The results of this trial showed that serum HbAlc, insulin, and HOMA-IR changed after 10 weeks of SIT and combined training in diabetic women compared to the baseline values. This study has demonstrated that personalized progressive SIT and combined training program performed 3 days/week for 10 weeks was effective in improving serum insulin, HOMA-IR, and HbA1c levels.

These findings seem to be consistent with the results of studies which found that high intensity training was accompanied by improved glycemic control in obese and/ or patients with type 2 diabetes (6,31). Several studies recently have shown that SIT appears to be a time-efficient exercise training that shares many of the metabolic adaptations with traditional endurance exercise training $(31,32)$.

However, few studies have assessed the impact of HIIT and combined (resistance and aerobic) training on glycemic control in patients with diabetes type $2(6,33,34)$. Recent randomized controlled clinical trial studies in patients with type 2 diabetes have reported improved glucose tolerance (35) following low-volume interval training, although most (36), but not all (10), have failed to improve HbA1c level and insulin resistance.

It seems that people with type 2 diabetes respond quite differently to SIT and combined training protocols. The mechanisms for the improvement in glycemic index observed after personalized SIT and combined training in the current study are unclear. It has been suggested that the improvement in HbAlc, insulin, FBG, and HOMA-IR 
levels following personalized SIT and combined training occurs via mechanisms different from standard aerobic and resistance training. It is likely that personalized SIT and combined exercise-induced abdominal subcutaneous adipose tissue reduction could be explained by the lowering of HbA1c, insulin, FBG, and HOMA-IR levels (37).

The mechanism by which SIT improves HbA1c, insulin, FBG, and HOMA-IR levels may lie in its ability to recruit more skeletal muscle fibers and rapidly deplete muscle glycogen contents, thereby increasing muscle insulin sensitivity (6).

However, combined exercise training had a longer total duration of exercise and caloric use compared to each type of training which was done alone. Although these patients tolerated this exercise mode, it seems that following this exercise protocol more calories were used.

Moreover, this study illustrated that after 10 weeks of exercise training, there were no significant differences between SIT and combined training in some glycemic control, $\mathrm{HbA1c}$, and FBG in type 2 diabetic individuals. However, in the present study, significant differences were found only in insulin and HOMA-IR indices between SIT and combined training protocols. The results support the hypothesis that HIIT can have different effects on insulin resistance. In addition, there are no other trials to compare these findings with their results. Our results are in agreement with previously published studies. In a study, Little et al illustrated that after 2 weeks of SIT, the average 24-h blood glucose concentration reduced in people with type 2 diabetes (19). Recently, Jung et al showed that insulin sensitivity improved in patients who performed HIIT compared with the control sedentary group (38). It has been shown that FBG levels reduced and skeletal muscle GLUT-4 levels increased by approximately 20 $\%$ following one week of HIIT and remained elevated over six weeks of training and a subsequent six weeks of detraining (39).

Significant decrease and improvement in $\mathrm{HbA1c}$, insulin, FBG, and HOMA-IR levels in the patient with diabetes type 2 demonstrated clinical importance. These results are notable because it suggests that this kind of exercise may have the potential to alter glycemic indices.

A novel finding of the present study was that following the implementation of personalized training, HbAlc levels reduced among the two experimental groups; however, patients with type 2 diabetes generally did not have a high percentage of improvement in HbA1c in SIT (14.25\%) and combined training $(7.14 \%)$ groups. However, there were acceptable improvements in FBG and insulin concentrations following personalized SIT and combined training. Although we did not find any significant reduction in FBG after combined training compared to SIT with a significant reduction in FBG. We found an acceptable improvement following SIT (42.85\%) and combined training $(35.71 \%)$ in FBG in patients with type 2 diabetes. Previous studies found that approximately more than $15 \%$ of patients fail to improve their glucose status and insulin resistance after different exercise training modalities. For example, Gregg et al (40) illustrated that a long-term multi-modal lifestyle intervention including exercise and diet interventions led to complete remission in approximately $9 \%$ of the patients.

Lack of long-term post-intervention follow-up is a certain limitation of this study. Another limitation of this study is that improvements in some body composition variables such as waist-hip ratio (WHR), WC, and body mass might not be only due to SIT or combined training, because it is possible that patients alter their diet in this study. It remains unclear whether or not patients altered their diet because we did not quantify the energy intake of them in the present study and there was no information about appetite changes following the interventions. These observations demonstrate that doing a low-volume SIT protocol (three times/week) can improve the health, body composition, and glycemic indexes in patients with type 2 diabetes.

\section{Conclusion}

Taken together, these results support the importance of the personalized exercise program. Some previous studies showed that combined training (aerobic and resistance) and SIT interventions could improve glucose homeostasis in overweight women with type 2 diabetes. Results highlight that individualized exercise training, independent of the mode of training, is an effective training method to improve body composition and glycemic control in overweight individuals with type 2 diabetes.

\section{Conflicts of interest}

Nil.

Ethical Approval

The study protocol was registered in the Iranian Clinical Trial Registry (IRCT20141118019995N10; http://www.irct.ir/trial/17753) and approved by the Research Ethics Committee of Shahrekord University under the code of SKU-94-210.

\section{Authors Contribution}

HG, ST, EB designed the study. HG and EB supervised exercise training protocols. EB, HG, ST supervised laboratory exams and data collection. HG, EB and ST analyzed and interpreted the data. $H G$, EB wrote the first draft of the manuscript. HG and EB edited the paper. All authors contributed to the writing of the paper. All authors read and approved the final manuscript

\section{Funding/Support}

This study was supported by a grant from Shahrekord University (98GRD30M895).

\section{Acknowledgements}

The authors would like to thank all participants of this study.

\section{References}

1. Støa EM, Meling S, Nyhus LK, Glenn S, Mangerud KM, 
Helgerud J, et al. High-intensity aerobic interval training improves aerobic fitness and $\mathrm{HbA} 1 \mathrm{c}$ among persons diagnosed with type 2 diabetes. Eur J Appl Physiol. 2017;117(3):455-67. doi: 10.1007/s00421-017-3540-1.

2. Marmett B, Nunes RB. Resistance and aerobic training in the treatment of type 2 diabetes mellitus. J Diabetes Metab Disord Control. 2017;4(5):150-4. doi: 10.15406/ jdmdc.2017.04.00126.

3. Liubaoerjijin $Y$, Terada T, Fletcher K, Boulé NG. Effect of aerobic exercise intensity on glycemic control in type 2 diabetes: a meta-analysis of head-to-head randomized trials. Acta Diabetol. 2016;53(5):769-81. doi: 10.1007/s00592-0160870-0.

4. Mendes R, Sousa N, Almeida A, Subtil P, Guedes-Marques $F$, Reis VM, et al. Exercise prescription for patients with type 2 diabetes-a synthesis of international recommendations: narrative review. Br J Sports Med. 2016;50(22):1379-81. doi: 10.1136/bjsports-2015-094895.

5. Kang SJ, Ko KJ, Baek UH. Effects of 12 weeks combined aerobic and resistance exercise on heart rate variability in type 2 diabetes mellitus patients. J Phys Ther Sci. 2016;28(7):208893. doi: 10.1589/jpts.28.2088.

6. Francois ME, Little JP. Effectiveness and safety of high-intensity interval training in patients with type 2 diabetes. Diabetes Spectr. 2015;28(1):39-44. doi: 10.2337/diaspect.28.1.39.

7. Gerhart DH, Pasternostro Bayles M. A comparison of CrossFit training to traditional anaerobic resistance training in terms of selected fitness domains representative of overall athletic performance. Int J Exerc Sci. 2014;9(2):Article 26.

8. Madsen SM, Thorup AC, Overgaard K, Jeppesen PB. High intensity interval training improves glycaemic control and pancreatic $\beta$ cell function of type 2 diabetes patients. PLoS One. 2015;10(8):e0133286. doi: 10.1371/journal. pone.0133286.

9. Mendes R, Sousa N, Garrido ND, Rocha P, José LTB, Reis VM. Efficacy of acute high-intensity interval training in lowering glycemia in patients with type 2 diabetes: diabetes $\mathrm{Em}$ movimento® pilot study. Br J Sports Med. 2013;47(10):e3-e. doi: 10.1136/bjsports-2013-092558.19.

10. Stephens NA, Sparks LM. Resistance to the beneficial effects of exercise in type 2 diabetes: are some individuals programmed to fail? J Clin Endocrinol Metab. 2015;100(1):43-52. doi: 10.1210/jc.2014-2545.

11. Higgins TP, Baker MD, Evans SA, Adams RA, Cobbold C. Heterogeneous responses of personalised high intensity interval training on type 2 diabetes mellitus and cardiovascular disease risk in young healthy adults. Clin Hemorheol Microcirc. 2015;59(4):365-77. doi: 10.3233/ch-141857.

12. Buford TW, Roberts MD, Church TS. Toward exercise as personalized medicine. Sports Med. 2013;43(3):157-65. doi: 10.1007/s40279-013-0018-0.

13. Dalleck LC, Van Guilder GP, Richardson TB, Vella CA. The prevalence of adverse cardiometabolic responses to exercise training with evidence-based practice is low. Diabetes Metab Syndr Obes. 2015;8:73-8. doi: 10.2147/dmso.s76880.

14. Buse JB, Caprio S, Cefalu WT, Ceriello A, Del Prato S, Inzucchi $\mathrm{SE}$, et al. How do we define cure of diabetes? Diabetes Care. 2009;32(11):2133-5. doi: 10.2337/dc09-9036.

15. Maiorana A, O'Driscoll G, Cheetham C, Dembo L, Stanton $\mathrm{K}$, Goodman C, et al. The effect of combined aerobic and resistance exercise training on vascular function in type 2 diabetes. J Am Coll Cardiol. 2001;38(3):860-6. doi: 10.1016/ s0735-1097(01)01439-5.

16. Sigal RJ, Kenny GP, Boulé NG, Wells GA, Prud'homme $D$, Fortier $M$, et al. Effects of aerobic training, resistance training, or both on glycemic control in type 2 diabetes: a randomized trial. Ann Intern Med. 2007;147(6):357-69. doi: 10.7326/0003-4819-147-6-200709180-00005.

17. D'Hooge R, Hellinckx T, Van Laethem C, Stegen S, De Schepper J, Van Aken S, et al. Influence of combined aerobic and resistance training on metabolic control, cardiovascular fitness and quality of life in adolescents with type 1 diabetes: a randomized controlled trial. Clin Rehabil. 2011;25(4):349-59. doi: 10.1177/0269215510386254.

18. Tokmakidis SP, Zois CE, Volaklis KA, Kotsa K, Touvra AM. The effects of a combined strength and aerobic exercise program on glucose control and insulin action in women with type 2 diabetes. Eur J Appl Physiol. 2004;92(4-5):437-42. doi: 10.1007/s00421-004-1174-6.

19. Little JP, Gillen JB, Percival ME, Safdar A, Tarnopolsky MA, Punthakee Z, et al. Low-volume high-intensity interval training reduces hyperglycemia and increases muscle mitochondrial capacity in patients with type 2 diabetes. J Appl Physiol. 2011;111(6):1554-60. doi: 10.1152/japplphysiol.00921.2011.

20. Gillen JB, Martin BJ, Maclnnis MJ, Skelly LE, Tarnopolsky MA, Gibala MJ. Twelve weeks of sprint interval training improves indices of cardiometabolic health similar to traditional endurance training despite a five-fold lower exercise volume and time commitment. PLoS One. 2016;11(4):e0154075. doi: 10.1371/journal.pone.0154075.

21. Banitalebi E, Kazemi A, Faramarzi M, Nasiri S, Haghighi MM. Effects of sprint interval or combined aerobic and resistance training on myokines in overweight women with type 2 diabetes: a randomized controlled trial. Life Sci. 2019;217:101-9. doi: 10.1016/j.lfs.2018.11.062.

22. Banitalebi E, Faramarzi M, Nasiri S, Mardaniyan M, Rabiee V. Effects of different exercise modalities on novel hepatic steatosis indices in overweight women with type 2 diabetes. Clin Mol Hepatol. 2019;25(3):294-304. doi: 10.3350/ cmh.2018.0086.

23. Banitalebi E, Mardaniyan Ghahfarrokhi M, Faramarzi M, Nasiri S. The effects of 10-week different exercise interventions on Framingham risk score and metabolic syndrome severity scores in overweight women with type 2 diabetes. Journal of Shahrekord University of Medical Sciences. 2019;20(1):1-8. doi: 10.34172/jsums.2019.01.

24. Bacchi E, Negri C, Zanolin ME, Milanese C, Faccioli N, Trombetta $M$, et al. Metabolic effects of aerobic training and resistance training in type 2 diabetic subjects: a randomized controlled trial (the RAED2 study). Diabetes Care. 2012;35(4):676-82. doi: 10.2337/dc11-1655.

25. Brzycki M. Strength testing--predicting a one-rep max from reps-to-fatigue. J Phys Educ Recreat Dance. 1993;64(1):88-90. doi: 10.1080/07303084.1993.10606684.

26. Larose J, Sigal RJ, Khandwala F, Kenny GP. Comparison of strength development with resistance training and combined exercise training in type 2 diabetes. Scand J Med Sci Sports. 2012;22(4):e45-54. doi: 10.1111/j.1600-0838.2011.01412.x.

27. Engel FA, Sperlich B, Stockinger C, Härtel S, Bös K, Holmberg $\mathrm{HC}$. The kinetics of blood lactate in boys during and following a single and repeated all-out sprints of cycling are different than in men. Appl Physiol Nutr Metab. 2015;40(6):623-31. doi: 10.1139/apnm-2014-0370.

28. Alkan BM, Özel S, Sütbeyaz ST, Çulha C. The effects of the aerobics exercise program on the cardiopulmoner capacity and disease symptoms of the patients with primary fibromialgia syndrome. Open J Rheumatol Autoimmune Dis. 2013;3(4):202-8. doi: 10.4236/ojra.2013.34031.

29. Shields N, Taylor NF. A student-led progressive resistance training program increases lower limb muscle strength in 
adolescents with Down syndrome: a randomised controlled trial. J Physiother. 2010;56(3):187-93. doi: 10.1016/s18369553(10)70024-2.

30. Mayhew JL, Brechue WF, Smith AE, Kemmler W, Lauber D, Koch AJ. Impact of testing strategy on expression of upperbody work capacity and one-repetition maximum prediction after resistance training in college-aged men and women. J Strength Cond Res. 2011;25(10):2796-807. doi: 10.1519/ JSC.0b013e31822dcea0.

31. Liu JX, Zhu L, Li PJ, Li N, Xu YB. Effectiveness of high-intensity interval training on glycemic control and cardiorespiratory fitness in patients with type 2 diabetes: a systematic review and meta-analysis. Aging Clin Exp Res. 2019;31(5):575-93. doi: 10.1007/s40520-018-1012-z.

32. Winding KM, Munch GW, lepsen UW, Van Hall G, Pedersen BK, Mortensen SP. The effect on glycaemic control of lowvolume high-intensity interval training versus endurance training in individuals with type 2 diabetes. Diabetes Obes Metab. 2018;20(5):1131-9. doi: 10.1111/dom.13198.

33. Shaban N, Kenno KA, Milne KJ. The effects of a 2 week modified high intensity interval training program on the homeostatic model of insulin resistance (HOMA-IR) in adults with type 2 diabetes. J Sports Med Phys Fitness. 2014;54(2):203-9.

34. Terada T, Friesen A, Chahal BS, Bell GJ, McCargar LJ, Boulé NG. Exploring the variability in acute glycemic responses to exercise in type 2 diabetes. J Diabetes Res. 2013;2013:591574. doi: 10.1155/2013/591574.
35. Revdal A. Low-Volume Interval Training Improves Cardiovascular Risk Factors in Type 2 Diabetes: A Randomized Controlled Trial. Norges Teknisk-Naturvitenskaplige Universitet, Det Medisinske Fakultet; 2014.

36. Fex A, Leduc-Gaudet JP, Filion ME, Karelis AD, AubertinLeheudre M. Effect of elliptical high intensity interval training on metabolic risk factor in pre- and type 2 diabetes patients: a pilot study. J Phys Act Health. 2015;12(7):942-6. doi: 10.1123/ jpah.2014-0123.

37. Simonsen L, Henriksen O, Enevoldsen LH, Bülow J. The effect of exercise on regional adipose tissue and splanchnic lipid metabolism in overweight type 2 diabetic subjects. Diabetologia. 2004;47(4):652-9. doi: 10.1007/s00125-0041374-y.

38. Jung ME, Bourne JE, Beauchamp MR, Robinson E, Little JP. High-intensity interval training as an efficacious alternative to moderate-intensity continuous training for adults with prediabetes. J Diabetes Res. 2015;2015:191595. doi: 10.1155/2015/191595.

39. Shaban N. The Effects of High Intensity Interval Training on Indices of Glucose Handling in Type 2 Diabetics [dissertation]. Ottawa: Library and Archives Canada; 2011.

40. Gregg EW, Chen H, Wagenknecht LE, Clark JM, Delahanty LM, Bantle J, et al. Association of an intensive lifestyle intervention with remission of type 2 diabetes. Jama. 2012;308(23):248996. doi: 10.1001/jama.2012.67929. 